\section{OPTIC NEURITIS IN ENCEPHALITIS LETHARGICA.}

By C. P. SYMONDS, M.A., M.D. OXoN., M.R.C.P., ASSISTANT PHYSICIAN FOR NIERVOUS DISLASES, GUY'S HOSPITAT, RADCLIFFE TRAVELIING FFLLOW OF OXFOIND UNIYYEIRSTTY.

IN searching the literature of encephalitis lethargica I have been able to find few references to changes in the fundus oculi or disturbance of visual function. Macnalty, ${ }^{1}$ in the Local Government Board Report of 1918, reports that in 50 cases the fundus oculi was systematically examined; in one case the retinal vessels were somewhat indistinct, but in no case was true papilloedema seen. Morax and Bollack, ${ }^{2}$ in a paper on ocular disturbances in encephalitis lethargica, state that they have never found any impairment of visual acuity, contraction of the fields, or changes in the fundus. On the other hand, Buzzard ${ }^{3}$ reports as encephalitis lethargica two cases showing papillœedema, both of which had symptoms of raised intracranial pressure, which were proved at operation to be caused by subdural extravasation of blood; microscopical examination of the brain in one of these cases showed changes typical of encephalitis lethargica; in the other the diagnosis appeared doubtful on clinical grounds, and there was no post-mortem. Vincent ${ }^{4}$ records two cases, diagnosed on good clinical evidence, in which visual acuity was grossly impaired and subsequently recovered, but he makes no mention of ophthalmoscopic examination.

Bramwell, ${ }^{5}$ in a paper dealing with a wide experience of the disease up till May, 1920, says that changes in the fundus oculi are seldom met with, "though in several cases $I$ have seen engorgement of the veins, and in two cases in which the diagnosis was not absolutely certain, and which are not included in this series, an optic neuritis was present."

\section{Record of Four Cases.}

The four cases which I am about to record were all seen during the past summer in the United States of America, where encephalitis lethargica appeared to be more prevalent in epidemic form than it was in Fingland during the same period. In each case definite changes were observed in the fundus oculi, together with clinical signs and changes in the cerebro-spinal fluid which favoured their inclusion in the encephalitis lethargica group.

CASE 1. - Ezra F., aged 37, was admitted to the Johns Hopkins Hospital on July 28th, 1920. Family history nil ad rem. Personal history: He is unmarried, a ship rigger by trade, has suffered with "rheumatism" since the age of 21, had gonorrhoea at 35; denies syphilis ; has never had any otorrhoea. Present illness : At the end of December, 1919, he had "influenza"; he cannot say whether he had fever, but felt chilly, had aches and pains all over, and sat by the fire all day. He was not especially drowsy; headache was not a prominent symptom; there was no diplopia. His vision seemed a little "dim," but he could read. He returned to work on Jan. 15th, 1920, but felt "droopy," and had aches and pains all over. About Feb. 1st he began to have spells of giddiness-whether he was doing heavy or light work made no difference; vision became misty, his eyes seemed to dance and he had occasional diplopia. He noticed also that " he had no accuracy in his work" "in tying up ropes, \&c., he had lost his sleight of hand. On Feb. 17th he gave up work again He then had pain in the right hip-joint, through the shoulders, and in the back of the neck. Stiffness and weakness of the right leg developed, and pain across the small of the back, with first retention of urine and then some degree of incontinence; no loss of control over anal sphincter. This passed off, but about March 15th there began feelings of numbness in the left arm and shoulder, followed by trembling in the same limb. In June began twitching movements in the right arm and leg, which cleared up after a while. About this time he noticed difficulty in remembering dates and names of persons, and trouble in pronouncing his words, with a tendency to elide syllables. He knew he was making mistakes, but his voice and tongue seemed stiff, so that he could not control them. He has felt a fluttering and jerking of his heart at times and a choking sensation in his chest. Frontal headaches bave been a constunt feature of his illness, but he has had no vomiting, no epileptic seizures, no uncinate attacks. Most of his symptoms have disappeared, but he complaing of stiffness, soreness, and headaches.

On examination he is a well-built, muscular man; temperature and pulse-rate normal; no evidence of diseasse other than in the nervous system. Mentally he is quiet, rather lethargic, but in good contact, and well oriented, memory for remote past good, for the period of his illness vague. He retains only five digits and shows constant tendency to transposition-e.g., 317,592 was repeated as 317,952 , and $9,416,375$ as $9,431,765$. Calculation is well performed, and his general grasp of information verg fair. In his mood he is depressed about his physical condition. He says he has been spending all his money trying to find out what is wrong. Vision: There is peripherall constriction of the visual fields (rough test); both optic disses show marked odema, and there is one diopter of swelling of the nasal edge of the left. No hæmorrhages. Hearing: Watch heard at 2 inches right and 4 inches left, with positive Rinne's test both sides (moderate degree of nerve deafness). Cranial nerves: Pupils normal; no ptosïs; extra-ocular movements good; nystagmoid jerkings on upward deviation. Slight weakness of right face in lower part.

Sensation: He misses a few cotton-wool touches on the left hand and arm, and says that he feels touches better on the left leg than the right, better on the left side of the face than the right. Vibration of a tuning-fork is appreciated poorly on the left hand, and there is some loss of sense of position in the fingers of this side. There is a zone of hyperæsthesia to pinprick around the trunk at the seventh dorsal level. The patient is a good witness and consistent in his answers. Motor system : There is general museular weakness; no spasticity nor atrophy, no localised palsy, no cerebellar defects. Reflexes: The tendon-jerks of both arms very brisk. The left epigastric weaker than the right. Abdominals brisk and equal. Knee-jerks brisk and equal. Right ankle-jerk greater than left. Plantar responses both extensor. Sphincters: Some difficulty in starting micturition.

Laboratory findings: Blood Wassermann negative Cerebro-spinal fluid: 70 cells mononuclears, ++ globulin. negative Wassermann, negative gold sol curve.

Summary.-Duration of illness eight months with varying symptoms of sensory and motor disturbance, both gemeral and visceral, and remittent course. Bilateral optic neuritis, patchy anæsthesia, general muscular weakness, extensos plantar responses, defective memory. Lymphocytosis and globulin in cerebro-spinal fluid.

The most interesting feature of this case is its ehronic. remittent course. I have now seen several such cases, and Economo ${ }^{67}$ has recorded one such with a fatal issue after an illness of nearly two years, during which the infective process remained smouldering with signs of extension from one part of the nervous system another, this being proved post mortem by the exist ence of inflammatory foci at various stages.

CAsE 2.-Edna J., aged 19, coloured, was admitted to the Johns Hopkins Hospital on July 27 th, 1920 , complaining of aching, stiffness, and pain in the legs and inability to walk properly. Previous history negative except for occasional attacks of headache and vertigo since the age of 15 . The present illness started suddenly on Jan. 1st, 1920, with headache, fever, and vomiting, stiffness of the neck, and pain on the left side of the head radiating down into the neck. She was admitted into the University Hospital, Baltimore, Jan. 2nd, where she was diagnosed cerebro-spimal fever. The cerebro-spinal fluid was cloudy, contained 720 cells pen cubic inch (sic), and globulin ++ . Smears and cultares negative for organisms. Wassermann reaction feebly positive in blood, negative in spinal fluid. She was discharged on Jan. 25th. She returned to her work as domestic servant in March. In May she began to have headaches, sna her ankles became stiff, numb, and heavy. She has alse complained of stiffness and soreness in the lumbar region. and of involuntary twitchings of the left arm. For the last two months her walking has been affected. There is no. history of convulsions or of any symptoms pointing te foreal brain lesion.

On examination she is a well-nourished, healthy working girl ; temperature and pulse-rate normal. Vision: There is a moderate degree of myopia. Acuity with glasses $20 / 20$. right and 20/70 left. The fields show concentric contraction. Both dises show hyperæmia, moderate engorgement of central veins, filling in of the physiological cups, and marked cedema amounting to $2 \mathrm{D}$ of swelling and extending out in to the retina. Hearing: Watch heard at 18 inches right and left. Cranial nerves normal; no defects of sensibility. Motor system: Tone, poser, and coordination: normal except for some flabbiness of the glutæi with almost complete bilateral paralysis of abduction at the hips. This accounts for her gait which is waddling with short steps, not unlike that sometimes seen in a muscular dystrophy. 

Reflexes: The tendon-jerks of the arms show a diminution
on the left. Epigastrics and abdominals not obtained. Knee- and ankle-jerks very feeble and equal. Plantar responses indefinitely flexor. Sphincters: Normal control. The patient was not feeling ill in herself and was up and about. She was discharged to the out-patient department for observation.

Summary.-Duration of illness seven months with acute onset of meningeal type and subsequent remissions including various sensory and motor symptoms. Bilateral optic neuritis, paralysis of abductors of hips with resultant wadding gait. Feebly positive W.R. in blood, lymphocytosis and ++ globulin in cerebro-spinal fluid.

Apart from the chronic course the main points of interest in this case are the acute meningeal onset, the pains, and the localised muscular palsies. Meningeal symptoms in encephalitis lethargica have been referred to by several observers, ${ }^{8} 91011$ and a case with pains and paralysis of multi-radicular distribution is recorded by Bassoe. ${ }^{12}$

CASE 3.-Esther W., aged 9, was admitted to the Children's Hospital, Boston, on August 3rd, 1920. The family history is negative. The patient had whooping-cough and bronchitis at 2 and measles at 5 . She is right-handed. The present illness began in January, 1920, when her teacher complaired that the child was dull and not getting on well at school; in using a ruler she would fail to rule a straight line. She complained to her mother of pains in the arms and legs and headaches, but continued at school. On March 1st involuntary movements of the left hand were noticed at table, and shortly afterwards twitching of the left side of the mouth. On March 15th her tonsils and adenoids were removed but she was up and about next day. Two days later she developed a high temperature and enlarged glands and was said to have the mumps. A week later, on getting out of bed to go to the lavatory, she was unsteady on her legs, and in the course of a day or two became paralysed from the knees down. There has been little change since, except that in June she had bouts of headache and vomiting for one week and has occasionally complained of "pins and needles" in her arms and legs. She has read a great deal during her illness and made no complaints about her eyes. There is no history to be obtained of convulsions.

Examination on Sept. 3rd, 1920, revealed a healthy-looking, well-nourished child. Rectal temperature $100^{\circ} \mathrm{F}$., pulse $80^{\text {. }}$ She is somewhat irritable, but her mental state is in no way abnormal. Vision: Acuity-she reads small print. The fields show a complete left homonymous hemianopia. Both optic dises show well-marked swelling with moderate engorgement of the veins; the change is more marked on the right, but swelling is less than $1 \mathrm{D}$. There is a small linear hæmorrhage on the nasal margin of the right disc. Hearing: Watch heard at 8 inches right and left. Oranial nerves: Pupils equal; right not quite central, being a little displaced inwards. Reactions to light and distance 13ormal. There is horizontal nystagmus on fixation to the right, the slow component being to the left. There is some weakness of the left face more marked in emotional than voluntary movement. No other defect. Sensation: In both hands a few cotton-wool touches are missed on the fingers, pinprick is not appreciated normally and there is imperfect sense of position. She is unable to recognise easily objects placed in her left hand, but this probably depends upon the paralysis of the fingers. There is definite impairment of sensation of cotton-wool and pinprick on both feet over an area corresponding to "boot" distribution. Sense of position in the toes is absent and vibration is not appreciated on the dorsum of either foot. The calves are more tender to deep pressure than are other muscle groups. Motor system: Involuntary movements of the left arm are the most striking feature. They are absent when the patient is quiet and at rest, but are brought into prominence when she is excited, and when she makes any vigorous bodily movement, especially if she makes an effort with her right arm. They consist of rhythmical alternating movements of the antagonistic groups of muscles, most marked in adductors and abductors of the shoulder, also pronation and supination of the arm, and extension and flexion of the wrist; the fingers are held flexed, and take no part in the movement, and there is a very little at the elbow-joint. The movements are of small amplitude, and in rate about three excursions per second. The limbs are atonic and there is some atrophy of the small muscles of the hands, especially the thenar groups. Both apper limbs show weakness of peripheral type, the left more than the right. The fingers of the left hand, however, remain in a position of flexion with some spasm, like the hand of a hemiplegic. The power of the trunk musculature appears normal. The lower limbs show complete bilateral, Haccid paralysis of the feet. On the left side the weakness extends to muscles at knee- and hip-joints, flexor and extensor groups being about equally affected. Reflexes: Tendon-jerks in arms and legs all absent, as also are abdominal and plantar reflexes. Sphincters: The child wil occasionally void in bed if she does not get the urinal at once. The cerebro-spinal fluid examined on August 17th showed 11 mononuclear cells. Von Pirquet's skin reaction negative. On Sept. 5th the condition was much the same evening temperature $100 \cdot 6^{\circ}$ rectal. On the 9th a second lumbar puncture yielded clear fluid containing 13 lympho cytes per cubic millimetre, no bacteria on examination negative culture; Wassermann reaction negative; gold sol curve negative. Physical condition unchanged.

Summary.-Duration of illness eight months, beginning with change in disposition, clumsiness of movements, and pains in arms and legs; subsequently weakness and in voluntary movements of left arm and face, febrile illness (? mumps), paralysis of legs. Bilateral optic neuritis, left homonymous hemianopia, rhythmic choreiform movements of left arm, flaccid palsy of lower limbs with absent tendonjerks, hypoæsthesia of glove and stocking distribution. Lymphocytosis in cerebro-spinal fluid.

The involuntary movements in this case were of a type frequently observed in the disease. ${ }^{14}$ 15 The polyneuritic symptoms were striking. Loss of tendon reflexes in encephalitis has been noted by Guillain, Draper ${ }^{17}$ has drawn attention to peripheral palsies of the lower limbs of lower motor neurone type, while Macnalty ${ }^{18}$ and Barker, Cross and Irwin, ${ }^{19}$ recognise a polyneuritic form of the disease. Hemianopia in a case of encephalitis lethargica has been recorded by Buzzard..$^{18}$

CASE 4.-Florence S., aged 10, was admitted to the Harriet Lane Home, Johns Hopkins Hospital, in July, 1920. The family history and previous history were negative. The story of the present illness is that in the middle of May she had a sudden attack of headache and vomiting; two weeks later her legs began to feel weak, and this weakness progressed rather gradually until she reached her present condition three weeks ago. She has had occasional attacks of headache and vomiting since the onset, but has never appeared really ill On Examination: She is an attractive child, somewhat undernourished, but appearing to be quite comfortable. There are no abnormalities apart from her central nervous system. Vision: Acuity and fields normal. The right optic disc shows a blurred nasal margin and the central vein is engorged. The upper margin of the left optic disc is also indistinct. The cranial nerves show no defect. Sensation: She misses nearly all cottonwool touches on the feet, the anæsthesia being of a "boot" distribution. There is also loss of sense of position in the toes of the feet, and to a lesser degree in all the fingers. Both calves are somewhat abnormally tender to pressure. Motor system shows very extensive weakness of the limbs, whicb is fairly even in its distribution, more marked in the lower limbs than the upper, and, if anything, more in the distal than the proximal muscles. The muscles of the pelvic girdle are involved, and she gets up from the supine position very much after the manner of a mpopathic. In the fingernose-finger and diadokokinesis tests she shows marked awkwardness, probably due to weakness. Reflexes: Arms : triceps present and equal; biceps and supinator absent Epigastrics: Right tires before left. Abdominals present and equal. Knee-and ankle-jerks absent. Plantar responses feebly flexor. Sphincters normal. Gait is unsteady and somewhat of the "steppage" type on a wide base.

Laboratory findings: Blood Wassermann negative. Cerebro-spinal fluid shows 28 cells, all mononuclears, + globulin, and negative Wassermann.

Summary.-Duration of illness three months, beginning acutely with headache and vomiting; subsequently progressive weakness of legs. Haziness of both optic discs, impairment of sensation in feet and hands, gross weakness of legs and arms, with loss of tendon-jerks. Lymphocytosis and + globulin in cerebro-spinal fluid.

This case presented a purely polyneuritic picture; except for the changes in the fundus and the cerebrospinal fluid findings, it would have been diagnosed as infective polyneuritis. It would hardly have been included in the present series had it not been for the link afforded by Case 3.

\section{Differential Diagnosis.}

Since we are at present unable. to identify the causal virus of encephalitis lethargica, and are without any serological test of positive value, the diagnosis of the disease in cases which do not come to post-mortem must largely depend on the exclusion of other possibilities. The title encephalitis lethargica, originally proposed by Economo and now universally established, is in many ways unfortunate. It is now 
generally recognised by all who have had wide experience of the epidemic that there are many cases which at no time display lethargy, and that the degree to which the brain is affected is extremely variable, while any part of the nervous system may be involved in the diffuse inflammatory process. In fact, Barker, Cross, and Irwin, ${ }^{11}$ in a recent review of the disease as it has appeared in the U.S.A., have discarded the title encephalitis lethargica, and give tbeir paper under the heading "On the Epidemic Acute and Subacute Non-suppurative Inflammations of the Nervous System Prevalent in the U.S.A. in 1918-19," including encephalitis, encephalomyelitis, polyneuritis, and meningo-encephalo-myeloneuritis. They assume as the cause a single infectious agent which attacks the central and peripheral cerebrospinal nervous system and its coverings in a widespread, though at the same time a patchy or disseminated way. If this definition of encephalitis lethargica be accepted the cases here recorded may all be included under it.

Taking them severally, No. 1 hardly admits of any other diagnosis than encephalitis lethargica after the exclusion of syphilis by the serological tests. In No. 2 the original diagnosis was cerebro-spinal fever, but the negative bacteriological findings in the cerebrospinal fluid and the subsequent clinical course were against this. In Nos. 3 and 4 poliomyelitis had to be considered.

Hertz, Johnson, and Depree ${ }^{20}$ have reported as acute polio-encephalo-myelitis the case of a boy, aged $12 \frac{1}{2}$, with acute onset of left hemiplegia and subsequent development of mild pyrexia, flaccid palsy of both legs with absent tendon-jerks, paralysis of the left abducens, atrophy of the left half of the tongue, and bilateral optic neuritis. The cerebro-spinal fluid contained "numerous lymphocytes and polymorphs." Later there was slight wasting in the muscles of the affected limbs. The symptoms cleared up in the course of a year leaving a residual left hemiparesis with the usual signs. Batten ${ }^{21}$ in his comprehensive review of poliomyelitis refers to a single case, that of a child supposed to have poliomyelitis who became permanently blind as the result of her illness, and says "there was slight swelling of the disc but no marked optic neuritis." Peabody, Draper, and Dochez ${ }^{22}$ found no abnormalities of the optic nerve in those of their cases which were examined, and in reviewing the complete literature of poliomyelitis up to 1912 quote Wickman as recording optic neuritis in a single acute case, Tedeschi who found optic atrophy and blindness in one eye in a chronic case, and Muller who found no abnormalities of the fundus in a large number of acute cases. Concerning polyneuritis in anterior poliomyelitis Peabody, Draper, and Dochez ${ }^{22}$ say nothing. Batten ${ }^{21}$ includes a polyneuritic type in his clinical classification of the disease, but later concludes that there is no good clinical evidence that the virus of poliomyelitis can give rise to a polyneuritic picture. It may be said, therefore, that Cases 3 and 4 do not correspond with any recognised type of anterior poliomyelitis. Moreover, all four cases described in this paper became ill at a time of year at which the seasonal incidence of poliomyelitis was low, and while this disease was not present in epidemic form, though encephalitis lethargica was prevalent.

The polyneuritic picture in Cases 3 and 4 at once reminded the writer of cases of acute febrile polyneuritis seen in France during the war, in which, as Holmes ${ }^{23}$ has described, the paralysis of the limbs was relatively uniform in comparison with other forms of polyneuritis, the distal muscles being not much more severely involved than the proximal groups, and there was surprisingly little sensory involvement, loss of deep sensibility being more pronounced than superficial anæsthesia. In acute febrile polyneuritis, however, Holmes found no changes in the cerebro-spinal fluid, in contradistinction to the cases recorded above.

Optic Neuritis in Disseminated Myclitis.

In relation to the four cases at present under discussion it is worth while to consider the disease long known as acute disseminated myelitis. Under this purely anatomical heading have been included a number of cases of obscure pathology characterised by the presence of widespread patches of nonsuppurative inflammation in the spinal cord.

Devic, ${ }^{24}$ in 1894 , first drew attention to the occasional occurrence of optic neuritis in this disease. Dreschfeld, ${ }_{3}^{26}$ also in 1894, recorded two cases of it with optic neuritis, in one of which careful microscopic examination showed inflammatory changes in the optic nerves. In discussing the retiology he says that the toxic agents which so often give rise to peripheral neuritis may also affect the spinal cord and quotes Fuchs's ${ }^{26}{ }^{27}$ statement that in multiple peripheral neuritis very similar changes are sometimes seen in the optic nerves. Several papers have since been published recording new cases of this syndrome-F. Taylor, ${ }^{26}$ J. Taylor and Collier, ${ }^{29}$ Clowes, ${ }^{30}$ and Hillion. ${ }^{31}$ The last-named writer was able to collect 45 cases from the literature, in one of which observed by Weill and Gallivardin ${ }^{32}$ there were found acute diffuse myelitis of the lower dorsal cord and lumbar enlargement, double optic neuritis, early peripheral neuritis, and diffuse round-celled infiltration of the cerebral cortex. Microscopical examination ${ }^{33}$ of the tissues, however, showed changes unlike those found in the recent epidemic of encephalitis lethargica.

None of the four cases here recorded corresponds clinically with the picture of acute disseminated myelitis, the main points of difference being the absence of gross sensory loss and sphincter disturbance; but the involvement of the optic nerve in one form of diffuse inflammation of the nervous system raises the probability of its occurrence in another.

\section{Summary.}

1. Four cases are reported in which optic neuritis was associated with signs of widespread lesions of the nervous system.

2. Despite individual points of resemblance none of these cases corresponds with the clinical picture of acute disseminated myelitis, anterior poliomyelitis, or acute febrile polyneuritis.

3. If the definition put forward by Barker, Cross, and Irwin ${ }^{11}$ be accepted, the clinical signs of all four cases are consistent with the diagnosis of encephalitis lethargica.

4. In Case 2 the Wassermann reaction in the blood was feebly positive. In the blood of Cases, 1, 3, and 4, and in all four cerebro-spinal fluids, the Wassermann reaction was negative.

5. In all four cases the cerebro-spinal fluid showed changes consistent with the diagnosis of encephalitis lethargica.

6 . In the association of optic neuritis with acute dis. seminated myelitis we have an instance of involvement of the optic nerves in a diffuse inflammatory process affecting the nervous system, which is analogous to the association of optic neuritis with encephalitis lethargica.

My thanks are due to Dr. W. S. Thayer and Dr. John Howland, of the Johns Hopkins Hospital, and Dr. Stewart, of the Children's Hospital, Boston, for permission to publish my notes on their cases.

References.-1. Macnalty, A. S. : T.G.B. Reports, New Series, 1918 No. 121, p. 22. 2. Morax, V., et Bollack, $j$.: Bull. et Mém. Soc. Méd de Hôp. de Paris, 1920 , ze sér. 44, 199-203. 3. Buzzard, E. F. THE LANCET, Dec. 2lst, 1918. 4. Vincent, C. : Bull. et Mém. Soc. Méd de Hop. de Paris, 1920, 3e sćr. 44, 316-7. 5. Bramwell, E.: The LANCET May 29th, 1920. 6. THE LANCET, August 21st, 1920, p. 412 7. Economo: Wiener Archir ftir Innere Medizin, Bd. $1 .$,
Hft. 2, June, 1920. 8. Lhermitte: Jour. Ann. de Méd., 1919, 6, 320. 9. Bramwell, E.: Loc. cit. 10. Hall, A. J. : THE LANCET, April 20th, 1918, p. 568. 11. Barker, L. F., Cross, E. S., and Irwin, S. V. : Amer. Jour. Med. Sc, 1920, 159, 157-93, 337-53. 12. Bassoe, P.: Jour. Amer. Med. Assoc., 1920, 1xxiv., 1009-12.
13. Buzzard, E. F.: Loc. cit. 14. Buzzard, E. F.: Proc. R.S.M., 1919, 13. Buzzard, E. F.: Loc. cit. 14. Buzzard, E. F.: Proc. R.S.M., 1919,
vol. xii., 9, Neur., 56. 15. Marie, P., et Levy, G.: Rev. Neurologicue 1920, vi., 513. 16. Guillain, G.: Bull. Acad. de Méd, 1920, 3e sér, 1xxxiii, 197-8. 17. Draper, G.: L.G.B. Reports, New Series, 1918, No. 131, p. 62. 18. Macnalty, A. S.: Loc. cit., p. 27.
19. Barker, Cross, and Irwin; Loc. eit. 20. Hertz, Johnson, and Depree: Guy's Hosp. Reports, 1913, p. 105. 21. Batten, F. E. : Brain, 1916, p. 174. 22. Peabory, F. W., Draper, G., and Duchez, A. R. Rockefeller Monos., No. 4, 1912, 1. 65. 23. Holmes, G.: THE LANCET, July 14th, 1917, p. 37. 24. Devic: Congrès Frane. de Méd. Paris 1894, p. 434. 25. Dreschfeld: THE LANCIT, June 2nd, 1894, p. 1174 26. Fuchs: D. Zeitsch. f. Nerven, 1893, p. 38. 27. Fuchs: Text-book of Ophthalmology, Amer, edition, 1917, p. 621. 28. Taylor, F.: Guy's Hosp. Reports, 1896, p. 45. 29. Taylor, J., and Collier, Jas. : Brain, 1901 p. 532 30. Clowes, E. S. : THF LANCET, March $23 \mathrm{rd}, 1912$, p. 782 31. Hillion; These de Paris, 1907. 32. Weill et Gallivardin : Rev Neur, October, 1903. 33. Weill et izll' vardin: Lyon Médical,
Angust 9th, 1903 . 